NASA/TM-1999-209180

N. 14

r.

A Space Experiment to Measure the Atomic Oxygen Erosion of Polymers and Demonstrate a Technique to Identify Sources of Silicone Contamination

Bruce A. Banks, Kim K. de Groh and Elyse Baney-Barton

Glenn Research Center, Cleveland, Ohio

Edward A. Sechkar

Dynacs Engineering Company, Inc., Brook Park, Ohio

Patricia K. Hunt, Alan Willoughby, Meagan Bemer, Stephanie Hope, Julie Koo, Carolyn Kaminski, and Erica Youngstrom Hathaway Brown School, Shaker Heights, Ohio

Prepared for the 34th Intersociety Energy Conversion Engineering Conference (IECEC) sponsored by the Society of Automotive Engineers, Inc.

Vancouver, British Columbia, August 1-5, 1999

National Aeronautics and

Space Administration

Glenn Research Center 


\section{Acknowledgments}

The authors gratefully acknowledge the assistance of Christy Haytas in the preparation of this paper.

This report is a preprint of a paper intended for presentation at a conference. Because of changes that may be made before formal publication, this preprint is made available with the understanding that it will not be cited or reproduced without the permission of the author.

Available from

NASA Center for Aerospace Information

7121 Standard Drive

Hanover, MD 21076

Price Code: A03
National Technical Information Service 5285 Port Royal Road

Springfield, VA 22100

Price Code: A03 


\title{
A SPACE EXPERIMENT TO MEASURE THE ATOMIC OXYGEN EROSION OF POLYMERS AND DEMONSTRATE A TECHNIQUE TO IDENTIFY SOURCES OF SILICONE CONTAMINATION
}

\author{
Bruce A. Banks, Kim K. de Groh and Elyse Baney-Barton \\ National Aeronautics and Space Administration \\ Glenn Research Center \\ Cleveland, Ohio \\ Edward A. Sechkar \\ Dynacs Engineering Company, Inc. \\ Brook Park, Ohio \\ Patricia K. Hunt, Alan Willoughby, Meagan Bemer, Stephanie Hope, \\ Julie Koo, Carolyn Kaminski, and Erica Youngstrom \\ Hathaway Brown School \\ Cleveland, Ohio
}

\begin{abstract}
A low Earth orbital space experiment entitled, "Polymers Erosion And Contamination Experiment," (PEACE) has been designed as a Get-A way Special (GAS Can) experiment to be accommodated as a Shuttle in-bay environmental exposure experiment. The first objective is to measure the atomic oxygen erosion yields of $\sim 40$ different polymeric materials by mass loss and erosion measurements using atomic force microscopy. The second objective is to evaluate the capability of identifying sources of silicone contamination through the use of a pin-hole contamination camera which utilizes environmental atomic oxygen to produce a contaminant source image on an optical substrate.
\end{abstract}

\section{INTRODUCTION}

\section{Atomic Oxygen Erosion Yield Measurements}

Since the advent of low Earth orbital (LEO) spacecraft, such as the U.S. Space Shuttle, the Russian Mir Space Station and International Space Station, the oxidative and erosive effects of low Earth orbital atomic oxygen have had significant consequences upon the design and durability of spacecraft materials. Atomic oxygen in low Earth orbit is formed by photodissociation of diatomic oxygen by short wavelength ultraviolet radiation from the sun in an environment where the mean free path is sufficiently large that the probability of recombination or the formation of ozone is improbable. As a result, spacecraft orbiting the Earth run into the atomic oxygen with ram energies of $\sim 4.5 \mathrm{eV}$. Both the impact energy as well as the high reactivity of atomic oxygen results in oxidative erosion of most hydrocarbon polymer materials. In-space data to measure the sensitivity of materials to atomic oxygen erosion are commonly quantified in terms of the atomic oxygen erosion yield, which is the volume of material which is removed per incident oxygen atom. Measurements of atomic oxygen erosion in space have been performed on numerous spacecraft by many investigators (refs. 1 to 3 ).

The atomic oxygen erosion yield of most polymeric materials (with the exception of silicones and materials containing metal atoms which produce nonvolatile oxides), is typically in the range of $0.337 \times 10^{-24}$ to $6.3 \times 10^{-24} \mathrm{~cm}^{3} /$ atom (ref. 3). This wide range of atomic oxygen erosion yields spanning more than an order of magnitude does not give great comfort to spacecraft designers who need to know, more accurately, the durability of typical spacecraft materials. Because in-space testing is expensive with available space being limited, many materials have not been tested in space. In addition, new materials continue to emerge which are in need of atomic oxygen erosion yield characterization for them to be accepted for use by spacecraft designers. Ground laboratory testing has been used with varying degrees of success to assist in providing prediction of in-space durability (ref. 2). In addition 
to ground-based testing, analytical models have been developed which are useful in predicting in-space atomic oxygen erosion yields based on the content and structure of hydrocarbon polymers (ref. 4).

The determination of atomic oxygen erosion yields from in-space exposure data has been dominated by the measurement of mass loss or thickness loss of samples exposed to either a fixed or a sweeping direction arrival atomic oxygen. Although the most reliable erosion yield data have been dominated by high fluence space experiments such as the Long Duration Exposure Facility (LDEF), which received fixed direction arrival of atomic oxygen, (ref. 5), most LEO spacecraft have surfaces which are exposed to atomic oxygen in a manner which sweeps at various angles across the surface during each orbit. Such sweeping arrival may have influences on the atomic oxygen erosion yield of the material. Thus, it is desirable to measure the atomic oxygen erosion yield for materials exposed to atomic oxygen arriving from a variety of directions and to be able to do so in a manner that reasonable uncertainty exists over the range of expected erosion yields. It is the intent of this proposed experiment to be able to make such measurements for a wide variety of polymeric materials. These results can then serve as a materials durability database as well as contribute to erosion yield predictive modeling techniques. This database will enhance the confidence in predictive techniques with the goal that accurate results could be achieved without requiring in-space characterization of every new material.

\section{Silicone Contamination and Atomic Oxygen Interactions}

The exposure of bulk silicones to atomic oxygen results in the oxidation of methyl groups which causes shrinkage and hardening of the surface of the silicones, and surface conversion of silicone to silica (refs. 6 and 7). Spacecraft exposed to the LEO environment for long durations such as the LDEF and Mir Space Station have indicated significant deposits of silica on nonsilica containing surfaces (ref. 5). This is a result of volatile silicone species depositing on surfaces which are exposed to atomic oxygen resulting in the conversion of silicone to silica (ref. 5). Depending on the composition of such oxidized silicone contaminants, UV darkening of the contaminant can occur, thus changing the solar absorptance properties which has the potential for altering the thermal balance of the spacecraft or diminishing the output of photovoltaic arrays. Perhaps what is most disturbing in many spacecraft experiments is that the source of the silicone contamination is not well understood. It is the intent of this experiment to demonstrate a technique for imaging sources of the silicone contamination.

\section{SPACE EXPERIMENT}

\section{Objective Summary}

The Polymer Erosion And Contamination Experiment (PEACE) is a collaborative research effort between Hathaway Brown School and the NASA Glenn Research Center under the sponsorship of the American Chemical Society (ACS). Project planning began in 1998 when ACS afforded Hathaway Brown School the opportunity to conduct an experiment using a Get-Away Special (GAS Can) reservation to conduct an experiment in the space shuttle bay. The PEACE objectives were developed to address atomic oxygen interaction issues related to polymer erosion and silicone contamination for spacecraft operating in the low Earth orbital (LEO) environment. The objectives of the experiment are to: (1) measure the atomic oxygen erosion yield of $\sim 40$ different polymeric materials, and (2) to evaluate the feasibility of identifying sources of silicone contamination using pin-hole contamination cameras which utilize atomic oxygen to produce images of the sources of contamination.

\section{Approach}

The overall drawing of the PEACE GAS Can experiment is shown in figure 1. To accomplish the first objective of the experiment, two types of thin polymer samples are to be used to allow for mass loss measurements as well as recession measurements to be made. The mass loss measurements will be used to calculate the atomic oxygen erosion yield of the samples, $E_{s}$, from the following equation. 


$$
E_{s}=\frac{\Delta M_{s}}{A_{s} \rho_{s} F_{k}}
$$

where

$\Delta \mathrm{M}_{\mathrm{s}}$ mass loss of polymer sample

$A_{s} \quad$ area of polymer sample

$\rho_{\mathrm{s}} \quad$ density of sample

$\mathrm{F}_{\mathrm{k}} \quad$ atomic oxygen fluence measured by Kapton $\mathrm{H}$ polyimide witness samples

The atomic oxygen fluence measured by Kapton $\mathrm{H}$ polyimide witness samples is:

$$
F_{k}=\frac{\Delta M_{k}}{A_{k} \rho_{k} E_{k}}
$$

where

$$
\begin{array}{ll}
\Delta M_{k} & \text { mass loss of Kapton } H \text { witness sample } \\
A_{k} & \text { area of Kapton } H \text { witness sample } \\
\rho_{k} & \text { density of Kapton } H \text { sample }=1.42 \mathrm{~g} / \mathrm{cm}^{3} \text { for Kapton Type } H \\
E_{k} & \text { erosion yield of Kapton } H \text { polyimide }=3.0 \times 10^{-24} \mathrm{~cm}^{3} / \mathrm{atom} \text { (ref. 3) }
\end{array}
$$

If the atomic oxygen fluence is predicted using the same sample size as the polymer test sample, then $A_{s}=A_{k}$ and the equation of the atomic oxygen erosion yield of the sample polymers is then given by:

$$
\mathrm{E}_{\mathrm{s}}=\frac{\Delta \mathrm{M}_{\mathrm{s}} \rho_{\mathrm{k}} \mathrm{E}_{\mathrm{k}}}{\Delta \mathrm{M}_{\mathrm{k}} \rho_{\mathrm{s}}}
$$

Because most polymers absorb water, accurate weight measurements require a consistent state of hydration to accurately determine the mass loss due to atomic oxygen exposure in space. To allow accurate measurements to be made, mass loss measurements will be made after vacuum dehydration of samples for at least $48 \mathrm{hr}$ prior to the exposure to air for immediate weighing. This results in the samples having minimal variation in weight because of their very low state of hydration.

Because the atomic oxygen fluence to which the samples will be exposed is not presently known, an additional more sensitive method will be used to measure atomic oxygen erosion yields by means of measurements of the recession of the polymer surfaces with respect to unexposed portions of the specimens. This will be accomplished by using either salt spray on polymers to deposit sodium chloride to protect sites on the polymer samples or by dusting with small mica flakes on the samples prior to flight. The salt or mica flakes, which are atomic oxygen durable, will be removed after flight to allow the use of atomic force microscopy to measure the erosion step between the protected and the exposed area of the polymers. This technique will also be used on the Kapton $\mathrm{H}$ atomic oxygen fluence witness samples to allow accurate atomic oxygen fluence measurements in the event of a low fluence flight. The atomic oxygen erosion yield of samples can be calculated from the atomic force microscopy recession data by the following equation:

$$
E_{s}=\frac{X_{s .0}-X_{s .1}}{F_{k}}
$$

where

$X_{S, 0}$ initial height of sample surface

$X_{S, 1}$ final height of sample surface

$F_{k} \quad$ atomic oxygen fluence measured by Kapton $\mathrm{H}$ polyimide witness samples 
For these measurements, the atomic oxygen fluence is given by equation (5):

$$
F_{k}=\frac{X_{k, 0}-X_{k, 1}}{E_{k}}
$$

where

$$
\begin{array}{ll}
X_{k, 0} & \text { initial height of Kapton } H \text { fluence witness sample } \\
X_{k, 1} & \text { final height of Kapton } H \text { fluence witness sample } \\
E_{k} & \text { erosion yield of Kapton } H \text { sample }=3 \times 10^{-24} \mathrm{~cm}^{3 / a t o m ~(r e f . ~ 3) ~}
\end{array}
$$

Thus, the erosion yield of the polymer samples is given by

$$
E_{s}=\frac{\left(X_{s, 0}-X_{s, 1}\right) E_{k}}{X_{k, 0}-X_{k, 1}}
$$

The second objective of the experiment involves the use of several sources of silicone contamination on one side of the GAS Can with pin-hole contamination cameras on the opposite side of the GAS Can (see fig. 1). The arrangement of silicone contamination samples allows atomic oxygen to impinge on the samples which are facing up but protects from atomic oxygen exposure the samples which are facing down. Both atomic oxygen exposed and non-exposed samples will be in view of contamination pin-hole cameras on the opposite side of the GAS Can. The silicones evolve from the samples, pass through an orifice in the pin-hole camera, and then deposit on iridiumcoated fused silica substrates which are also exposed to arriving atomic oxygen. Atomic oxygen impinging upon the depositing silicone contamination would convert the silicone to silica which would gradually increase in thickness with exposure duration in space. Upon retrieval from space, the silica contaminated iridium-coated fused silica substrates will then be optically characterized by means of scanning variable angle spectroscopic ellipsometry by Dr. John Woollam at the University of Nebraska at Lincoln, Nebraska to produce images of the contaminant sources. The technique is sufficiently sensitive that monolayer deposits are readily measurable. By having some silicone samples being exposed to atomic oxygen and others protected, it may be possible to determine what role, if any, atomic oxygen plays in the source of silicone contamination. If the technique proves viable, such contamination pin-hole cameras could then be used to look into the shuttle bay or on large space structures such as International Space Station to identify sources of silicone contamination.

\section{Apparatus}

The GAS Can for this experiment consists of an open ended cylinder to allow exposure of the samples and materials to occupy the space which is $\sim 58 \mathrm{~cm}$ in diameter. An overall assembly drawing of the experiment shown as an exploded view is given in figure 2 . The polymer samples for mass loss measurements will be $2.54 \mathrm{~cm}$ in diameter with desired thickness on the order of $0.05 \mathrm{~mm}$ thick. The polymer samples for erosion depth measurements will be only $1.27 \mathrm{~cm}$ in diameter and of similar thickness. Figure 3 shows a top view of the polymer sample tray and an exploded cross sectional view indicating how the sample is sandwiched between the top and bottom plate of the sample tray. There are 60 locations of both the large and small sized samples. This allows 40 polymer samples to be measured with respect to erosion yield hy both mass loss and surface recession with an additional 20 Kapton atomic oxygen fluence witness samples of each size to be distributed over the sample tray. The Kapton fluence witness samples will allow measurement of the spatial variation of atomic oxygen fluence which may occur as a result of Shuttle-caused shadowing of the incoming atomic oxygen if it is arriving at small angles with respect to the plane of the sample tray surface.

To obtain a qualitative understanding of the amount of atomic oxygen flux arriving from various directions two atomic oxygen pin-hole cameras will be used. Silver coated glass hemispheres will be used in conjunction with pinholes in orifice plates to make pin-hole cameras which allow atomic oxygen to oxidize silver to produce an image of the arrival direction of atomic oxygen during the entire space exposure. Figure 4 shows a drawing of one of the two atomic oxygen pin-hole cameras to be used in the experiment. The inside diameter of the glass hemispheres is 
$4.55 \mathrm{~cm}$ and the diameter of the orifices will be 0.51 and $1.27 \mathrm{~mm}$ in diameter. The purpose of having two different orifice diameters for the two atomic oxygen pin-hole cameras is to be confident that at least one of the cameras will have sufficient atomic oxygen fluence arrival to see the arrival direction and if a high fluence exposure occurs, the smaller pin-hole will allow more accurate angular determination.

The silicone contamination portion of the experiment is purposely mounted below the plane of the polymer samples to minimize contamination on the surface of the polymer samples. As can be seen from figure 1, there will be two contamination source assemblies each containing six silicone samples. Three of the samples will be exposed at $\sim 45^{\circ}$ with respect to the axis of the GAS Can to allow atomic oxygen to impinge upon the sample and to allow a line of sight to the contamination camera at the opposite side of the GAS Can cylinder. An additional three samples are facing downward such that incident atomic oxygen would be shielded from the samples, thus each contamination camera will view six samples. Figures $5(\mathrm{a})$ and (b) show drawings of a typical assembled contamination camera and an exploded view of the camera. The contamination cameras allow a small portion of the contaminant flux to enter through an orifice plate and deposit on an iridium-coated fused silica substrate. This substrate is oriented at $45^{\circ}$ with respect to the axis of the GAS Can. The camera tube is open to allow arriving atomic oxygen flux to convert deposited silicones to silica thus immobilizing the surface contaminants and allowing their gradual build up in thickness as normally occurs in space. The small orifice $(0.5 \mathrm{~mm}$ diameter) allows for images of the sources of contamination to form on the iridium-coated fused silica substrate.

\section{Exposure Considerations}

The atomic oxygen fluence needed for this experiment depends upon the uncertainty deemed acceptable for the erosion yield of the polymers tested and the technique used to compute these erosion yields (mass loss or surface recession measured by atomic force microscopy). For the mass loss samples, if one assumes that a typical sample will have an erosion yield and density of approximately that of Kapton $\mathrm{H}$ polyimide, then based on equations (1) to (3) the fractional uncertainty measured in terms of the standard deviation in erosion yield of the sample $\delta \mathrm{E}_{\mathrm{s}}$, divided by the erosion yield of the sample, $E_{s}$, is given by equation (4) where $\delta$ represents the standard deviation in their respective quantities.

$$
\frac{\delta E_{s}}{E_{s}}=\left[2\left(\frac{\delta \Delta M_{k}}{E_{k} A_{k} \rho_{k} F_{k}}\right)^{2}+2\left(\frac{\delta \rho_{k}}{\rho_{k}}\right)^{2}+\left(\frac{\delta E_{k}}{E_{k}}\right)^{2}\right]^{1 / 2}
$$

Where

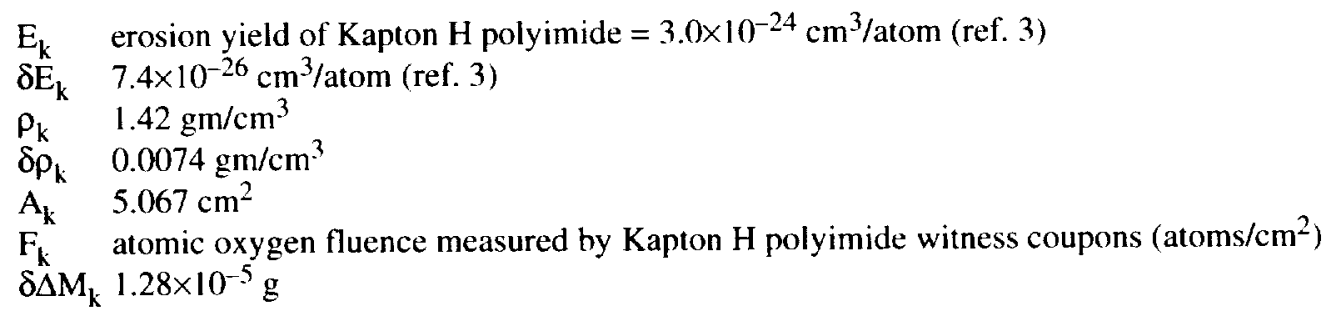

A similar equation can be developed for the fractional erosion yield uncertainty for the surface recession measurement samples.

The standard deviation in sample surface height is believed to increase with atomic oxygen exposure proportional to the square root of the atomic oxygen fluence in a manner following Poisson statistics. Thus, through experimental measurement, if one knows the standard deviation in sample height, $\delta \mathrm{X}_{\mathrm{k}, 0}$, after a known atomic oxygen fluence, $F_{k, 0}$ in space, one can predict the standard deviation $\delta X_{k, \ell}$, at an arbitrary fluence, $F_{k}$. Thus:

$$
\delta \mathrm{X}_{\mathrm{k}, \mathrm{t}}=\delta \mathrm{X}_{\mathrm{k}, 0} \sqrt{\frac{\mathrm{F}_{\mathrm{k}}}{\mathrm{F}_{\mathrm{k}, 0}}}
$$


One can use equations (6) and (8) along with data from a previous flight experiment to compute the following fractional uncertainty in erosion yield measured in terms of standard deviation of the erosion yield divided by the erosion yield as shown below:

$$
\frac{\delta \mathrm{E}_{\mathrm{s}}}{\mathrm{E}_{\mathrm{s}}}=\left[2\left(\frac{\delta \mathrm{X}_{\mathrm{k}}}{\mathrm{E}_{\mathrm{k}} \mathrm{F}_{\mathrm{k}}}\right)^{2}+2\left(\frac{\delta \mathrm{X}_{\mathrm{k}, 0}}{\mathrm{E}_{\mathrm{k}} \mathrm{F}_{\mathrm{k}}}\right)^{2} \frac{\mathrm{F}_{\mathrm{k}}}{\mathrm{F}_{\mathrm{k}, 0}}+\left(\frac{\delta \mathrm{E}_{\mathrm{x}}}{\mathrm{E}_{\mathrm{k}}}\right)^{2}\right]^{1 / 2}
$$

where

$$
\begin{array}{ll}
\mathrm{F}_{\mathrm{k} .0} & 4.8 \times 10^{19} \text { atoms } / \mathrm{cm}^{2} \\
\delta \mathrm{X}_{\mathrm{k} .0} & 2.28 \times 10^{-6} \mathrm{~cm} \\
\delta \mathrm{X}_{\mathrm{k}} & \text { standard deviation in sample height for unexposed Kapton } \mathrm{H} \text { polyimide }=8.4 \times 10^{-8} \mathrm{~cm} \\
\mathrm{E}_{\mathrm{k}} & 3.0 \times 10^{-24} \mathrm{~cm}^{3} / \text { atom } \\
\delta \mathrm{E}_{\mathrm{k}} & 7.4 \times 10^{-26} \mathrm{~cm}^{3} / \text { atom } \\
\mathrm{F}_{\mathrm{k}} & \text { atomic oxygen fluence measured by Kapton } \mathrm{H} \text { polyimide witness coupons atoms } / \mathrm{cm}^{2}
\end{array}
$$

The numbers used for the variables are based on a combination of literature values (ref. 3), experimental measurements and statistical studies performed by the authors.

Based on the mass loss and recession measurement technique, the fractional uncertainty as a function of atomic oxygen fluence can be plotted as shown in figures 6(a) and (b) for mass loss and recession measurements. Although one can feel most comfortable in interpreting mass loss data for samples, the standard deviation in erosion yield for a typical polymer material rises above 10 percent for atomic oxygen fluences less than $1 \times 10^{19}$ atoms $/ \mathrm{cm}^{2}$, whereas use of atomic force microscopy recession measurements has only a 6 percent uncertainty at the same fluence. Based on these two plots it appears that useful atomic oxygen erosion yield data will result provided the mission has an atomic oxygen fluence in excess of $1 \times 10^{19} \mathrm{atoms} / \mathrm{cm}^{3}$. For both measurement techniques the minimal uncertainty for high fluences is $\sim 3$ percent for fluences in excess of $5 \times 10^{19} \mathrm{~cm}^{2} /$ atom.

\section{Materials}

The 40 polymers currently being considered to be measured for atomic oxygen erosion yield are listed in table 1 . These materials represent a variety of polymers currently being used, or considered for use, in space as well as polymers which were specifically chosen to assist in providing in-space data to correlate with computational methods to predict erosion yields.

The silicone samples will consist of silicones typically used in space of varying degrees of volatility. The silicones currently being considered consist of dimethylethoxysilane (which is sprayed on the Shuttle tiles to increase their water repellency), DC-93-500 (typically used to attach cover glass to solar cells) and CV-1147 (which is used between the solar cells on the International Space Station).

\section{CONCLUSION}

The Polymers Erosion And Contamination Experiment (PEACE) has been designed to be accommodated in a Get-Away Special (GAS Can) experiment as an open can experiment in the Shuttle bay. Approximately 40 polymers will be evaluated to determine their atomic oxygen erosion yield by mass loss measurements as well as erosion depth through atomic force microscopy. The experiment will contain atomic oxygen pin-hole cameras to image the arrival flux in a qualitative manner impinging upon the samples. The experiment also contains 2 contamination cameras which are designed to image sources of contamination from silicone sources located below the polymeric sample plane. The development of the pictures of the sources of contamination will be achieved by first fixing the contaminants by exposure to atomic oxygen to convert silicone to silica. Scanning variable angle spectroscopic ellipsometry will then be used to measure the very small thicknesses of contaminants which should deposit in a manner that images their sources. The atomic oxygen fluence necessary to achieve $\sim 3$ percent uncertainty in results appears to be $5 \times 10^{19}$ atoms $/ \mathrm{cm}^{2}$. 


\section{REFERENCES}

1. Brinza, D.E.: "Proceedings of the NASA Workshop on atomic oxygen effects," JPL Publication 87-14, Pasadena, CA, June 1, 1987.

2. Banks, B.A., Rutledge, S.K., Paulsen, P.E., and Stueber, T.J.: "Simulation of the low Earth orbital atomic oxygen interactions with materials by means of an oxygen ion beam," NASA TM-101971, presented at the 18th Annual Symposium on Applied Vacuum Science \& Technology, sponsored by the American Vacuum Society, Clearwater Beach, FL, Feb. 6-8, 1989.

3. Banks, B.A.: "The use of fluoropolymers in space applications," Chapter 4 in Modern Fluoropolymers, edited by John Scheirs, John Wiley \& Sons, 1997.

4. Iskanderova, Z.A., Kleiman, J.I., and Gudimenko, Y., and Tennyson, R.C.: "Influence of content and structure of hydrocarbon polymers on erosion by atomic oxygen," J. Spacecraft \& Rockets, vol. 32:5, pp. 878-884, Sept.-Oct. 1995.

5. Silverman, E.M.: "Space Environmental Effects on Spacecraft: LEO Material Selection Guide," NASA CR-4661, Aug. 1995.

6. de Groh, K.K., and McCollum, T.A.: "Low Earth orbital durability of protected silicone for refractory photovoltaic concentrator arrays,” J. Spacecraft \& Rockets, vol. 32:1, Jan-Feb. 1995, pp.

7. Banks, B.A., de Groh, K.K., Rutledge, S.K., and DiFilippo, F. J.: "Prediction of in-space durability of protected polymers based on ground laboratory thermal energy atomic oxygen," NASA TM-107209, presented at the 3 rd International Conference for Protection of Materials and Structures from the LEO Spacecraft Environment, sponsored by the Canadian Space Agency and the Institute for Space and Terrestrial Studies, April 25-26, 1996.

TABLE I -POLYMER SAMPLES FOR EROSION YIELD CHARACTERIZATION

\begin{tabular}{|c|c|c|c|}
\hline & Material & Abbreviation & Trade Names \\
\hline $\mathbf{I}$ & Acrylonitrile butadiene styrenc & ABS & Cycolac; Lustran \\
\hline 2 & Cellulose acetate & $\mathrm{CA}$ & Cellidor; Tenite \\
\hline 3 & Cellulose nitrate & $\mathrm{CN}$ & Clelluloid; Xylonite \\
\hline 4 & Chlorotrifluoroethylene & CTFE & Kel-F \\
\hline 5 & Crystalline polyvinylfluoride w/white pigment & PVF & White Tedlar \\
\hline 6 & Diallyl diglycol and triallyl cyanurate & $\mathrm{ADC}$ & CR-39 \\
\hline 7 & Epoxide or epoxy & $\mathrm{EP}$ & Epoxy resin 5208 \\
\hline 8 & Ethylene/propylene/diene & EPTR,EPDM & Nordel; Keltan \\
\hline 9 & Tetrafluorethylene-ethylene copolymer & ETFE & Tefzel \\
\hline 10 & Ethylene vinyl acetate copolymer & EVAC/EVA & Evatane \\
\hline 11 & Ethylene vinyl alcohol copolymer & EVAL/EVOH & Clarene: Eval \\
\hline 12 & Fluorinated ethylene propylene & FEP/TFE-HFP & Teflon FEP \\
\hline 13 & Graphite & HOPG & Pyrolytic Graphite \\
\hline 14 & Halar ethylene-chlorotrifluoroethylene & ECTFE & Halar \\
\hline 15 & Polyimide (BPDA) & Pl & Upilex -S \\
\hline 16 & Melamine formaldehyde & MF & Melmex; Melopas \\
\hline 17 & Phenol formaldeyde & PF & Bakelite; Stemite \\
\hline 18 & Poly-(p-phenylenephthalamide) & PPTA & Kevlar 49, Twaren \\
\hline 19 & Polyamide 6 or nylon 6 & PA 6 & Akulon $\mathrm{K}$; Ultramid \\
\hline 20 & Polyamide 66 or nylon 66 & PA 66 & Maranyl; Zytel \\
\hline 21 & Polyacrylonitrile & PAN & Acrilan; Barex; Orlon \\
\hline 22 & Polybenzimidazole & PB] & Celazole \\
\hline 23 & Polycarbonate & PC & Lexan; Makrolon \\
\hline 24 & Polychlorotrifluorethylene & PCTFE & Hostaflon $\mathrm{C} 2 ; \mathrm{Kel}-\mathrm{F}$ \\
\hline 25 & Polyethylene & PE & Alathon; Lupolen \\
\hline 26 & Polyetheretherkeytone & PEEK & Victrex PEEK \\
\hline 27 & Polyethylene terephthalate & PET & Mylar, Arnite A: Techster E \\
\hline 28 & Polyinide (PMDA) & PI & Vespel; Kapton $\mathbf{H}$ \\
\hline 29 & Polymethyl methacrylate & PMMA & Plexiglas; Lucite \\
\hline 30 & Polypropylene & $\mathrm{PP}$ & Profax; Propathene \\
\hline 31 & Polyoxymethylene;acetal;poly formaldehyde & POM & Delrin; Celcon \\
\hline 32 & Polystyrene & PS & Lustrex: Polystyrol \\
\hline 33 & Polysulphone & PSU & Udel; Ultrason/S \\
\hline 34 & Polytetrafluoroethylene & PTFE & Fluon: Teflon: Halon \\
\hline 35 & Polyvinylidene chloride copolymers & PVDC & Saran \\
\hline 36 & Polyvinylidene fluoride & PVDF & Kynar \\
\hline 37 & Polyvinyl fluoride & PVF & Tedlar \\
\hline 38 & Pyrrone & PR, PMDA-DAB & Pyrrone \\
\hline 39 & Urea formaldehyde & UF & Beetle, Scarah \\
\hline 40 & Polyphenylene isophthalate & PPPA & Nomex \\
\hline
\end{tabular}




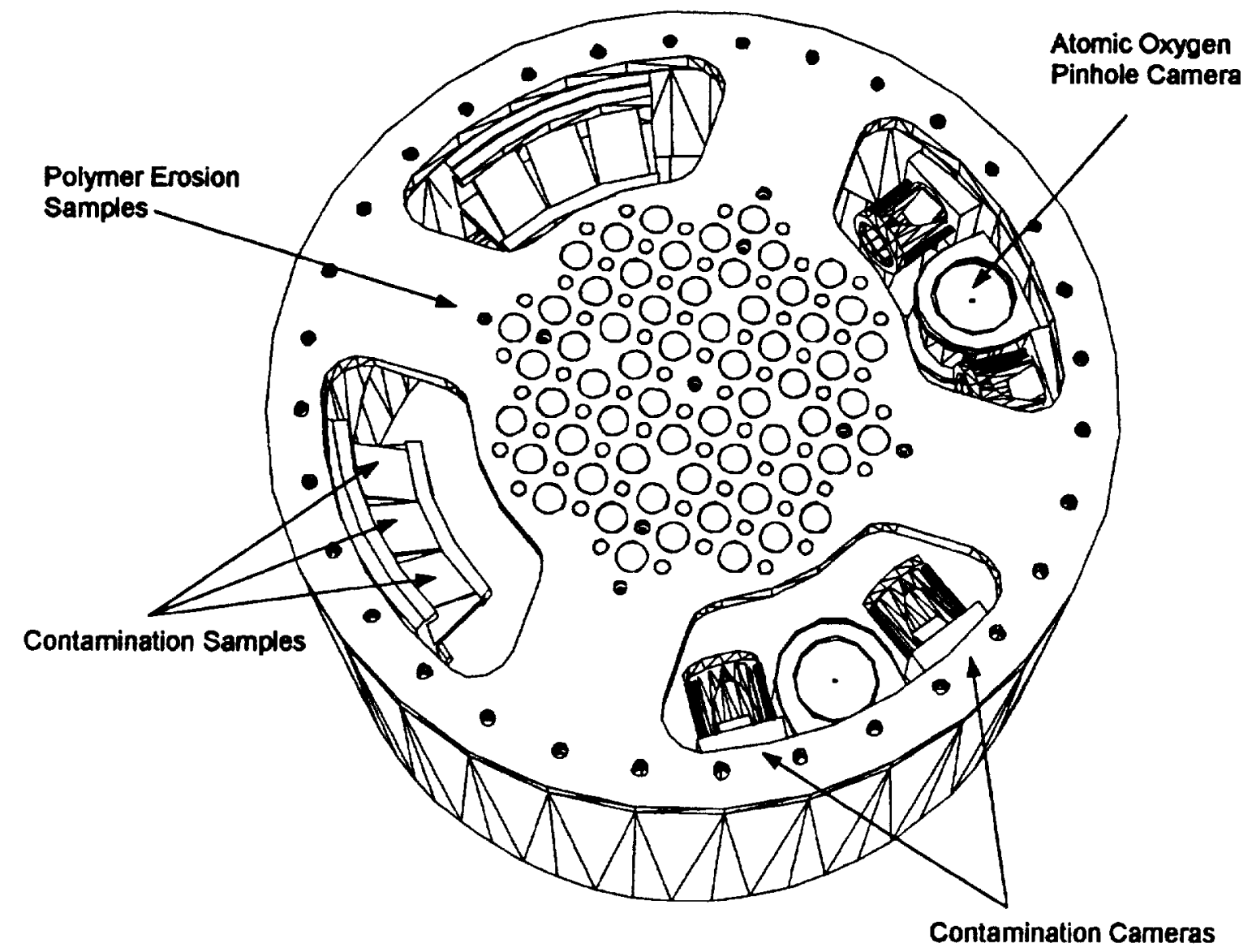

Figure 1.-Drawing of the Polymer Erosion and Contamination (PEACE) GAS can experiment. 


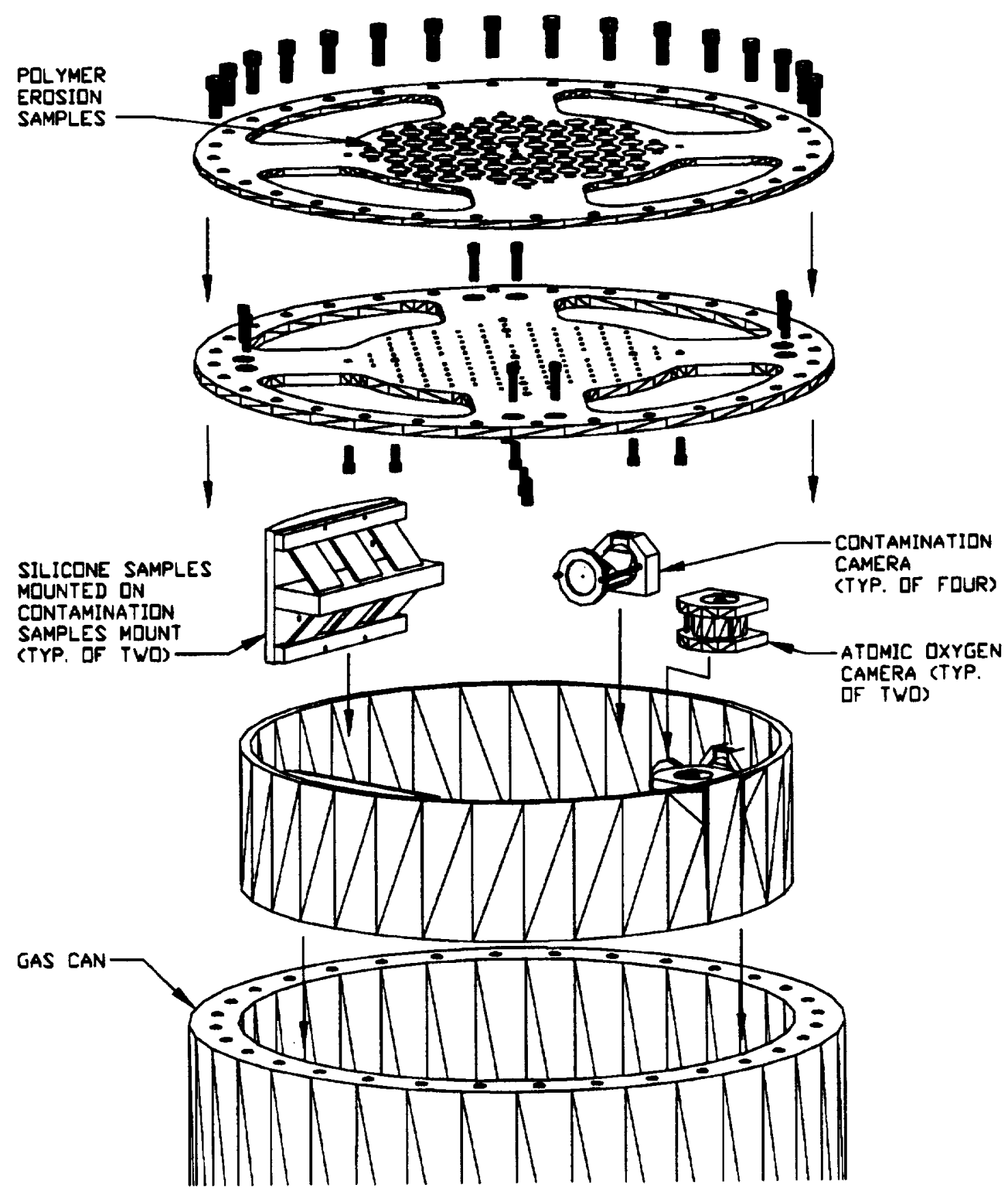

Figure 2.-Exploded view drawing of the experiment. 


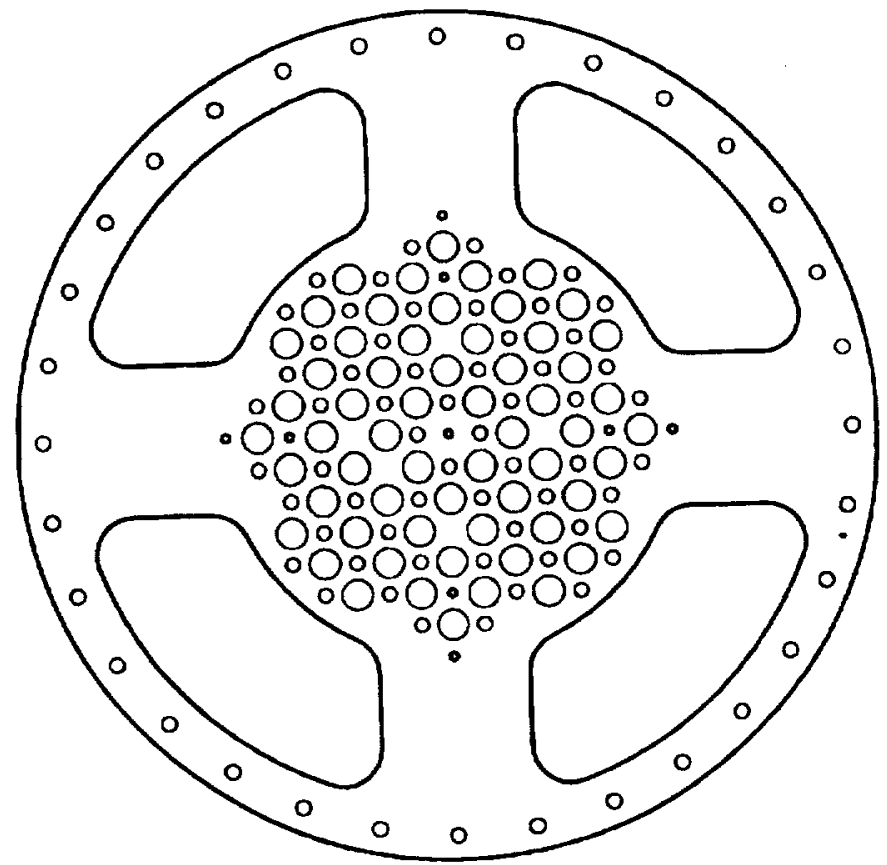

(a) Face view of sample tray.

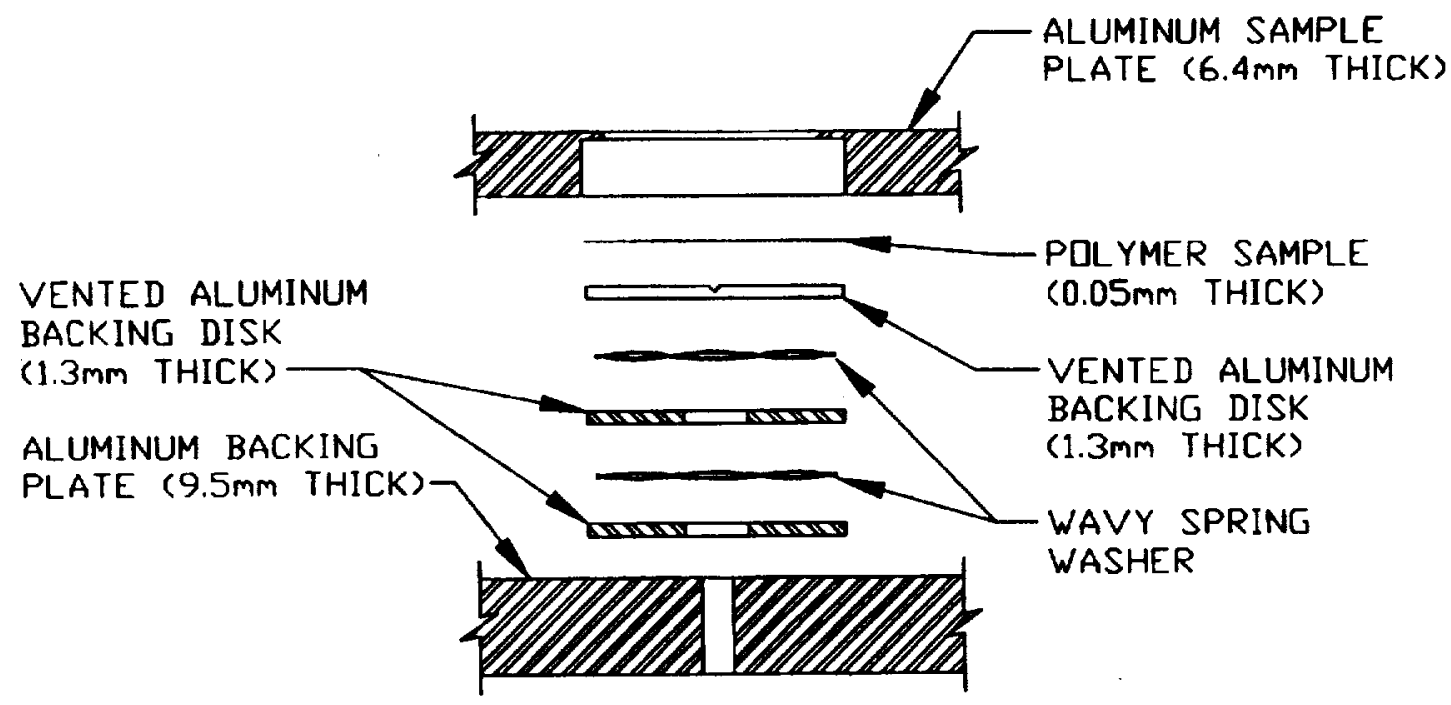

(b) Exploded section view of typical sample.

Figure 3.-Polymer sample tray. 


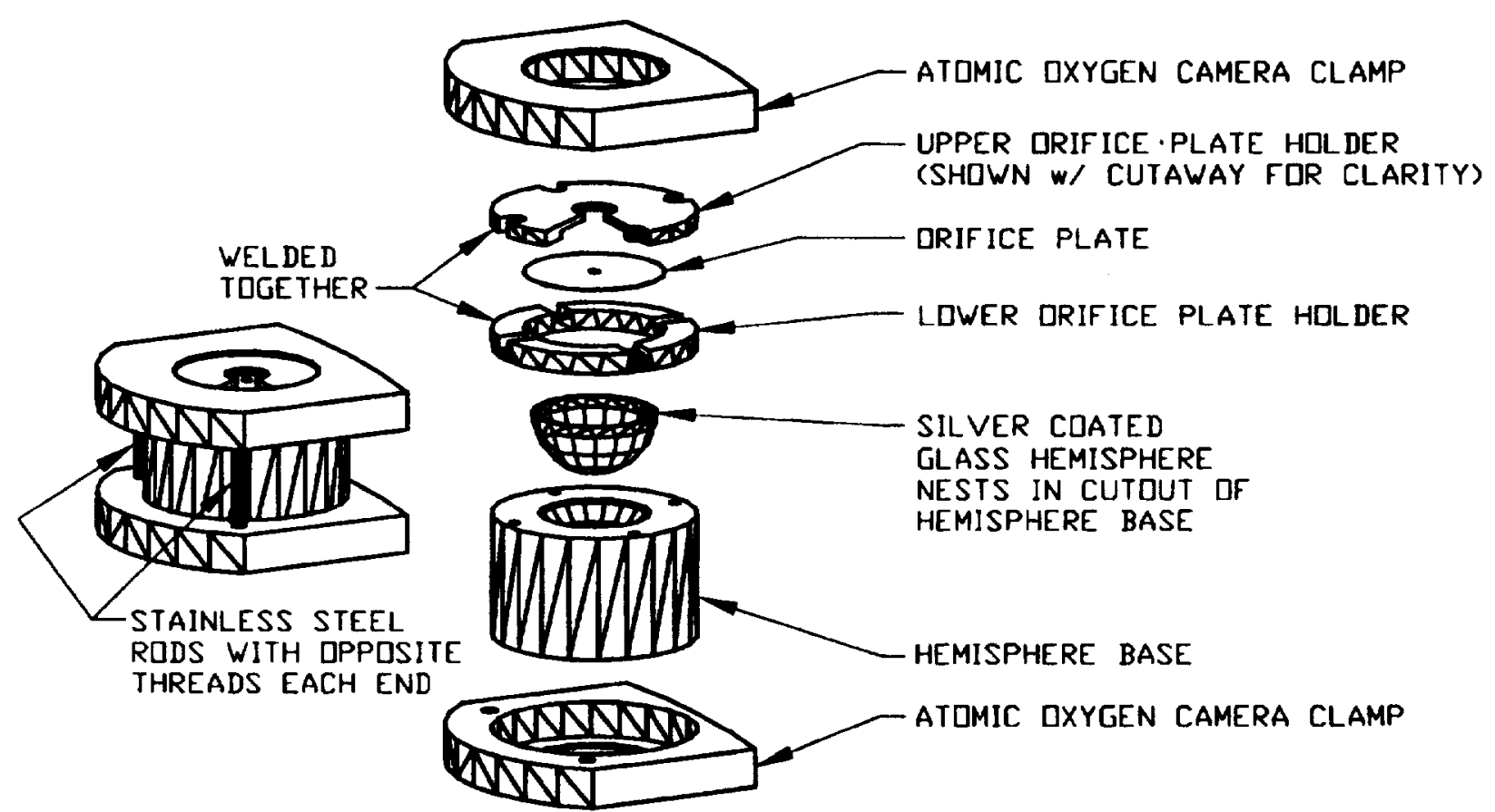

Figure 4.-Drawing of one of the atomic oxygen pinhole cameras to be used in the experiment. 


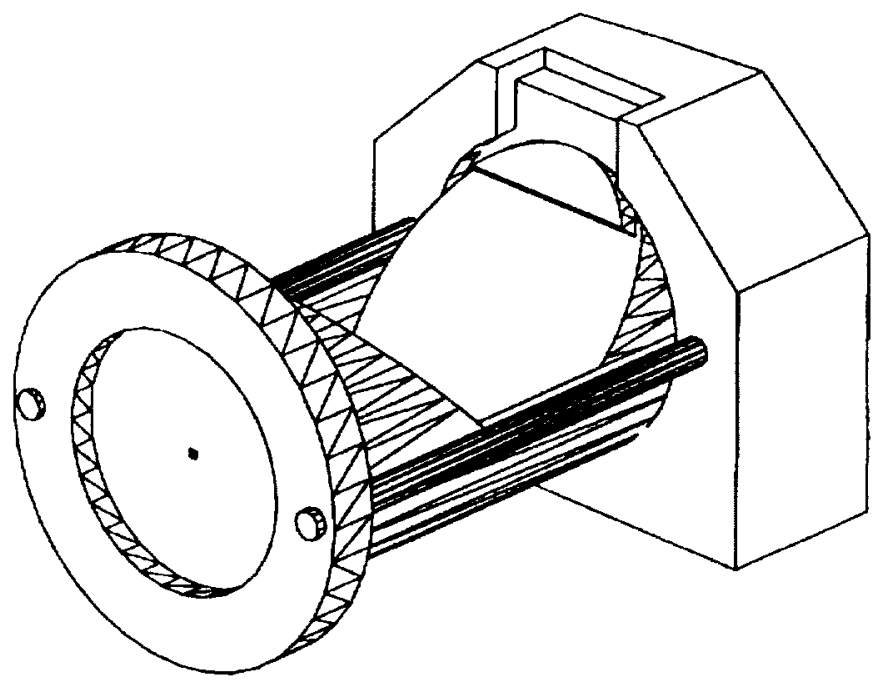

(a) Perspective assembly view.

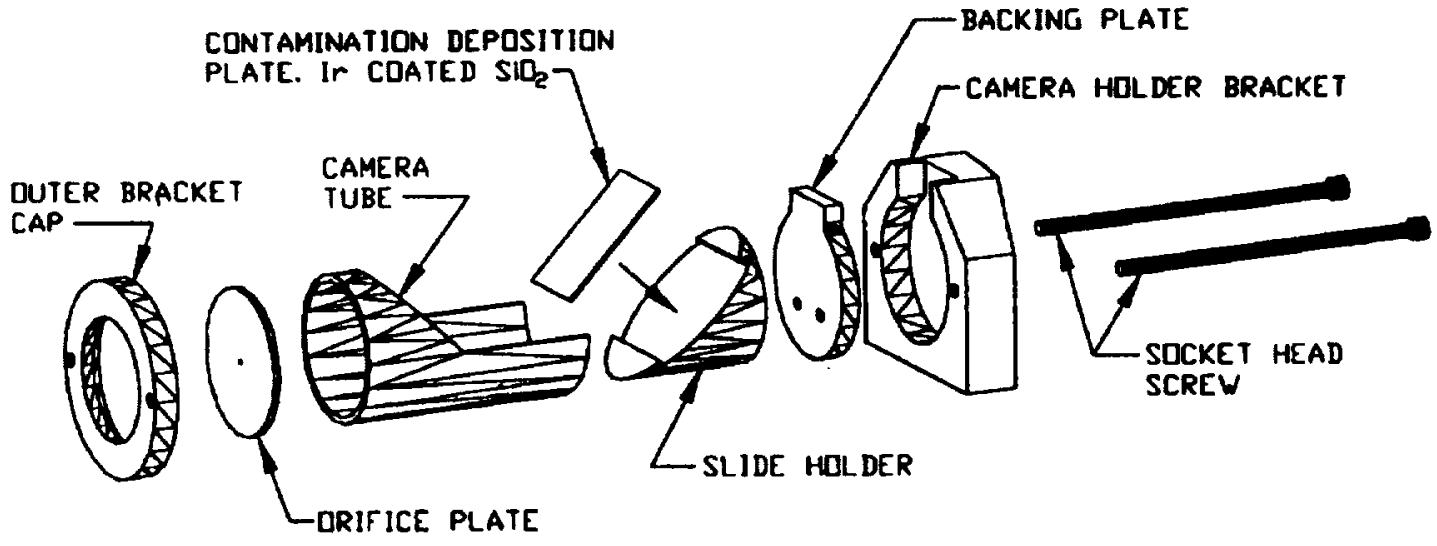

(b) Exploded view.

Figure 5.-Silicone contamination camera. 


\begin{tabular}{|c|c|c|c|c|}
\hline \multicolumn{3}{|c|}{ REPORT DOCUMENTATION PAGE } & \multicolumn{2}{|r|}{$\begin{array}{l}\text { Form Approved } \\
\text { OMB No. } 0704-0188\end{array}$} \\
\hline \multicolumn{5}{|c|}{ 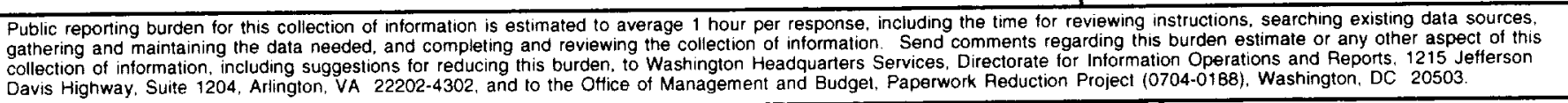 } \\
\hline 1. AGENCY USE ONLY (Leave blank) & $\begin{array}{r}\text { 2. REPORT DATE } \\
\text { May } 1999\end{array}$ & \multicolumn{3}{|c|}{$\begin{array}{l}\text { 3. REPORT TYPE AND DATES COVERED } \\
\text { Technical Memorandum }\end{array}$} \\
\hline \multicolumn{3}{|c|}{$\begin{array}{l}\text { 4. TITLE AND SUBTITLE } \\
\text { A Space Experiment to Measure the Atomic Oxygen Erosion of Polymers and } \\
\text { Demonstrate a Technique to Identify Sources of Silicone Contamination }\end{array}$} & \multicolumn{2}{|c|}{ 5. FUNDING NUMBEAS } \\
\hline \multicolumn{3}{|c|}{$\begin{array}{l}\text { 6. AUTHOR(S) } \\
\text { Bruce A. Banks, Kim K. de Groh, Elyse Baney-Barton, Edward A. Sechkar, } \\
\text { Patricia K. Hunt, Alan Willoughby, Meagan Bemer, Stephanie Hope, Julie Koo, } \\
\text { Carolyn Kaminski, and Erica Youngstrom }\end{array}$} & \multicolumn{2}{|c|}{$W U-632-1 A-1 E-00$} \\
\hline \multicolumn{3}{|c|}{$\begin{array}{l}\text { National Aeronautics and Space Administration } \\
\text { John H. Glenn Research Center at Lewis Field } \\
\text { Cleveland, Ohio } 44135-3191\end{array}$} & \multicolumn{2}{|c|}{ 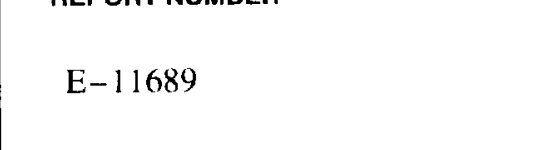 } \\
\hline $\begin{array}{r}\text { 9. SPONSORING/MONITORING AGE } \\
\text { National Aeronautics and } \mathrm{S} \\
\text { Washington, DC 20546-0r }\end{array}$ & $\begin{array}{l}\text { ENCY NAME(S) AND ADORESS(ES) } \\
\text { pace Administration } \\
001\end{array}$ & & \multicolumn{2}{|c|}{$\begin{array}{l}\text { 10. SPONSORING/MONITORING } \\
\text { AGENCY REPORT NUMBER } \\
\text { NASA TM-1999-209180 } \\
\text { 99IECEC-26 }\end{array}$} \\
\hline \multicolumn{5}{|c|}{$\begin{array}{l}\text { 11. SUPPLEMENTARY NOTES } \\
\text { Prepared for the 34th Intersociety Energy Conversion Engineering Conference (IECEC) sponsored by the Society of } \\
\text { Automotive Engineers, Inc., Vancouver, British Columbia, August I-5, 1999. Bruce A. Banks, Kim K. de Groh and Elyse } \\
\text { Baney-Barton, NASA Glenn Research Center; Edward A. Sechkar, Dynacs Engineering Company, Inc., 2001 Aerospace } \\
\text { Parkway, Brook Park, Ohio (work funded under NASA Contract NAS3-98022); Patricia K. Hunt, Alan Willoughby, } \\
\text { Meagan Bemer, Stephanie Hope, Julie Koo, Carolyn Kaminski, and Erica Youngstrom, Hathaway Brown School, Shaker } \\
\text { Heights, Ohio. }\end{array}$} \\
\hline \multirow{2}{*}{\multicolumn{3}{|c|}{ 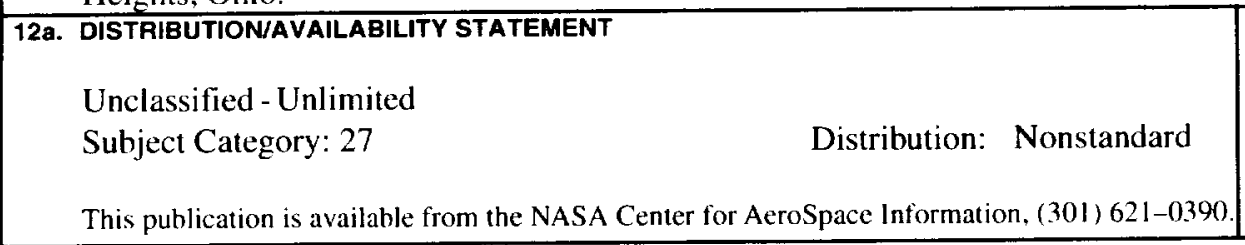 }} & \multirow{2}{*}{\multicolumn{2}{|c|}{ 12b. DISTRIBUTION CODE }} \\
\hline & & & & \\
\hline \multicolumn{5}{|c|}{ 13. ABSTRACT (Maximum 200 words) } \\
\hline \multicolumn{5}{|c|}{$\begin{array}{l}\text { A low Earth orbital space experiment entitled, "Polymers Erosion And Contamination Experiment", (PEACE) has been } \\
\text { designed as a Get-Away Special (GAS Can) experiment to be accommodated as a Shuttle in-bay environmental exposure } \\
\text { experiment. The first objective is to measure the atomic oxygen erosion yields of approximately } 40 \text { different polymeric } \\
\text { materials by mass loss and erosion measurements using atomic force microscopy. The second objective is to evaluate the } \\
\text { capability of identifying sources of silicone contamination through the use of a pin-hole contamination camera which utilizes } \\
\text { environmental atomic oxygen to produce a contaminant source image on an optical substrate. }\end{array}$} \\
\hline \multicolumn{3}{|l|}{ 14. SUBJECT TERMS } & & $\begin{array}{c}\text { 15. NUMBER OF PAGES } \\
19\end{array}$ \\
\hline \multirow{2}{*}{\multicolumn{3}{|c|}{ Atomic oxygen; Erosion yield; Silicone contamination }} & & 16. PRICE CODE \\
\hline & & & & \begin{tabular}{|c|}
$\mathrm{A} 03$ \\
20 LIMITATION OF ABSTRACT
\end{tabular} \\
\hline $\begin{array}{l}\text { 17. SECURITY CLASSIFICATION } \\
\text { OF REPORT }\end{array}$ & $\begin{array}{l}\text { 18. SECURITY CLASSIFICATION } \\
\text { OF THIS PAGE }\end{array}$ & $\begin{array}{l}\text { 19. SECURITY CLASSIFI } \\
\text { OF ABSTRACT }\end{array}$ & ATION & \\
\hline Unclassified & Unclassified & Unclassified & & \\
\hline
\end{tabular}




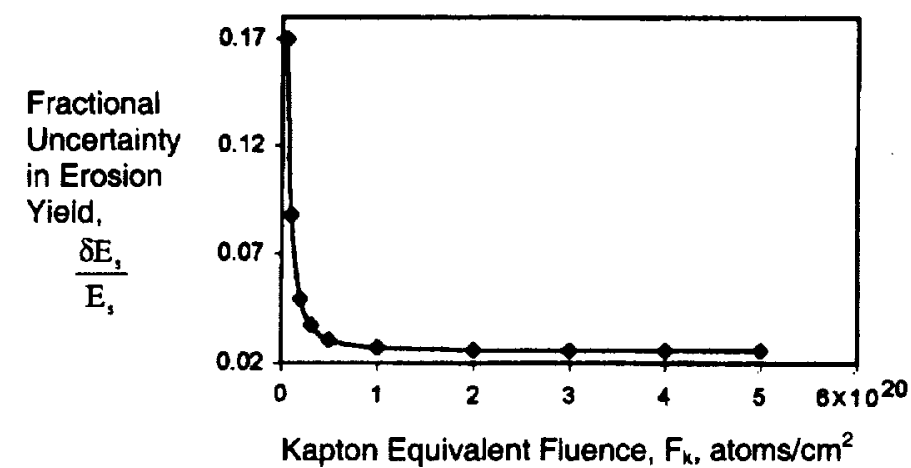

(a) For mass loss samples.

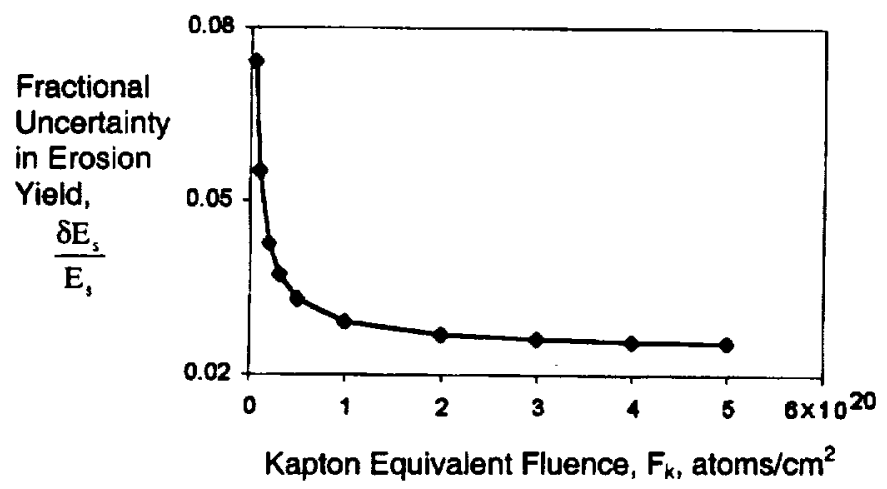

(b) For atomic loss microscopy samples.

Figure 6.-Fractional uncertainty of erosion yield measured in terms of standard deviation and erosion yield divided by erosion yield as function of atomic oxygen fluence for polymer samples. 